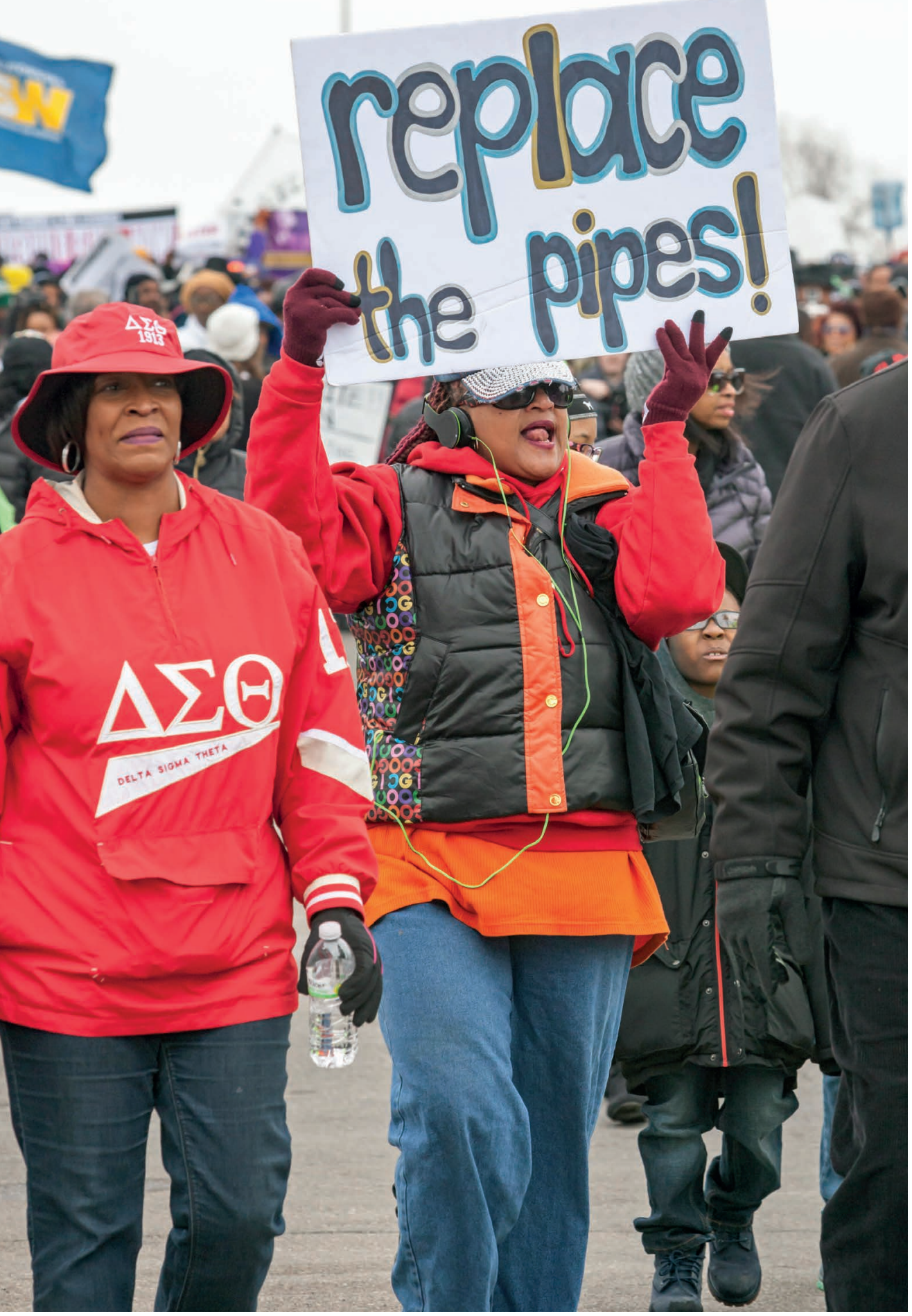

Residents of Flint, Michigan, march in 2016 to demand that lead water pipes in the city be replaced.

PREVENTIVE MEDICINE

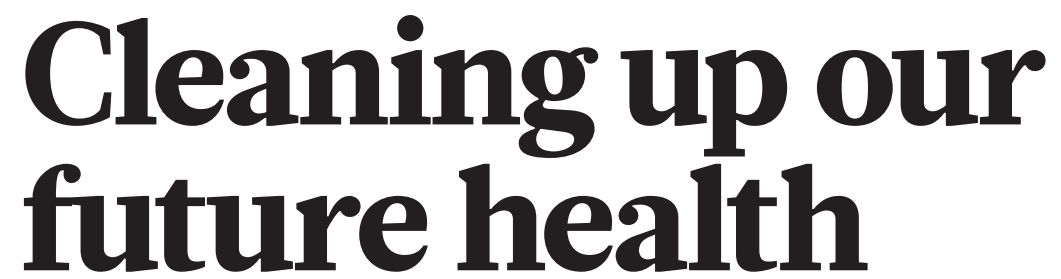

Can an evidence-based approach help to strengthen the case for limiting people's exposure to toxic chemicals?
$\mathrm{P}$ ollutants are everywhere. They can be found in the water that we drink, the air that we breathe and the food that we eat, and they are taking a toll on our health. In 2015 , pollution was estimated to have caused almost 9 million deaths worldwide - three times more than those from AIDS, tuberculosis and malaria combined.

Pollution can have a negative impact on health at any point in a person's life. Often, the full effects are not seen for decades. Unborn babies and young children, for example, are especially vulnerable to the effects of methylmercury, a widespread pollutant that accumulates in fish and seafood and can cause intellectual disability and vision and hearing losses. According to a 2013 study (T. M. Attina \& L. Trasande. Environ. Health Perspect. 121, 1097-1102; 2013), exposure to lead in childhood had a negative effect on IQ that resulted in an economic cost to low- and middle-income countries of around 977 billion international dollars (a unit of currency devised to account for differences in purchasing power between countries). And in the past two decades, evidence that exposure to particulates in the air are linked to dementia has begun to build.

Mercury, lead and air pollution are found throughout the environment. They are among ten pollutants highlighted by the World Health Organization as chemicals that pose a considerable threat to public health. The neurological problems that they can cause, for which treatment is often lacking, are especially concerning. "In the past decade, there has been a steady increase in the incidence of neurological disorders, and a great deal of these brain problems have been linked to exposure to different pollutants," says Philip Landrigan, a paediatrician and epidemiologist in the Icahn School of Medicine at Mount Sinai in New York.

Although the risks they pose are great, there is little understanding of the effects on health of many common chemicals. Since 1950, more than 140,000 new chemicals have been synthesized, of which around 5,000 are now ubiquitous in the environment. Despite people's regular exposure to these compounds, a wide-ranging study led by Landrigan reported that fewer than half of these chemicals have been tested for safety or toxicity in humans.

"The failure to test widely used chemicals for their potential toxicity represents a failure of governments to act on behalf of their citizens, and failure of the chemical-manufacturing industry to take responsibility for the products it produces," he says. "We are conducting a massive toxicological experiment in the world today and our children, our grandchildren and future generations are the unwitting, unconsenting subjects."

\section{THE QUEST FOR EVIDENCE}

Before the health burden of pollution can be reduced, the compounds responsible must be identified. Researchers gather such evidence 
from two main sources. One is epidemiological studies that match exposure to a chemical - determined by its presence in the blood or urine - to the likelihood of developing a medical condition. The other is laboratorybased studies of a chemical's effects in animals. Together, data from these sources represent the bulk of the evidence that is used to build a case against a pollutant, and to convince policymakers of the need to ban or restrict it. But the process takes time.

"It takes over a decade for adequate toxicological and epidemiological data to be amassed to even begin making rational decisions about a chemical's risk to human health," says Jonathan Martin, a toxicologist at Stockholm University. In part, this is down to the interpretation of results. "Toxicological data can always be criticized because it is done in animals or cells with questionable relevance to humans," Martin says. And even when an epidemiological study shows statistical associations between chemical exposure and adverse health effects, it cannot provide unequivocal evidence for causation on its own.

As a result, vast amounts of data must be collected to build a solid case for removing a chemical from the environment, including findings made in a variety of species of animal. "Only when the toxicological effects that are observed in animals are the same ones that show up in humans in many large and wellconstructed epidemiological surveys is there enough information to perhaps take regulatory action against a chemical," says Martin. The building of evidence is therefore just the start of the journey down the long road towards a chemical's withdrawal from use.

\section{SAFE EXPOSURE}

Removing a pollutant from use entirely is difficult. Inaction by regulatory bodies is one issue that hinders the process. Lead - for many years, a common component of paint, water pipes and petrol - is now known to be highly toxic. In the past decade, thousands of studies have drawn links between lead exposure and the development of numerous health problems, including reduced cognitive function in children and adults. But although lead has now been banned in certain applications, evidence of its negative effects on health existed for many decades before policies on exposure were changed, even as safer alternatives were developed. "This long delay was the direct consequence of fierce opposition and incessant political lobbying by the lead industry," says Landrigan.

A similar story lies behind the decision in March 2016 by the US Environmental Protection Agency (EPA) to allow farmers to continue to use the pesticide chlorpyrifos, in direct contravention of advice from the agency's own scientists. An agricultural ban on the pesticide - which was phased out of residential use in the United States in 2000, owing to its neurological effects - was opposed by manufacturers

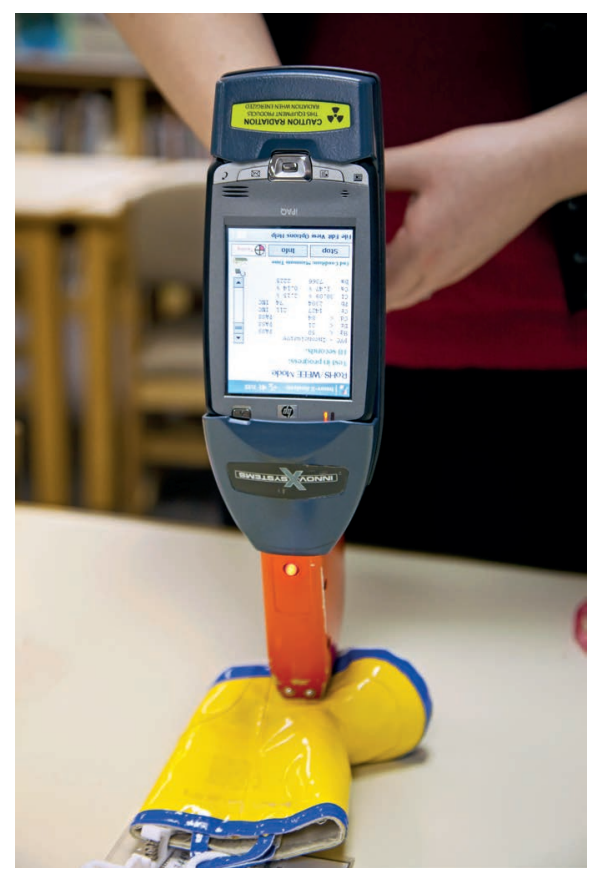

A hand-held X-ray fluorescence spectrometer is used to test for toxic chemicals in a child's boot.

such as Dow AgroSciences of Indianapolis, Indiana, and industry groups such as the American Farm Bureau Federation, based in Washington DC. In the weeks preceding the verdict, Scott Pruitt, administrator of the EPA, is reported to have told the bureau that US President Donald Trump's administration was "looking forward to working closely with the agricultural community" "The decision flies in the face of clear evidence," says Landrigan. "As a paediatrician," he adds, "I find Pruitt's decision to be scientifically reprehensible and morally repugnant."

Even when regulatory bodies decide to take action against a pollutant, actually doing so often proves difficult. One of the trickiest aspects for researchers and authorities to negotiate is the level of exposure that is deemed 'safe'.

The neurological effects of lead have been shown to occur even at what are considered to be low levels of exposure. "Decades of

\section{"We are conducting a massive toxicological experiment in the world. today."}

research demonstrate,

quite conclusively, that there is no safe level of lead exposure," says David Bellinger, a neurologist at the Harvard T. H. Chan School of Public Health in Boston, Massachusetts. The result is that the greatest burden of disease associated with lead comes not from people who experience high levels of exposure, but from those who encounter only low or moderate levels in the environment. Although harm to an individual is greater at higher levels of exposure, low-level exposure is a bigger problem for health-care systems. "You are more likely to get sick or die from heavy exposure to lead, for example, but your case will be just one of a handful," says Bruce Lanphear, an environmental health researcher at Simon Fraser University in Burnaby, Canada. "A lot more people will get sick from low-to-moderate-level exposure."

Known as the 'prevention paradox', this concept also applies to a number of other pollutants with no known safe level of exposure, including airborne particulates and asbestos. And it poses a considerable problem to regulatory bodies - with no safe level, everyone is at risk, and health-care systems are not set up to tackle such a wide-ranging problem, says Lanphear. Preventive interventions at the population level "are difficult to implement in a health system dominated by medical care which is designed to treat disease", he says.

Although efforts have been made to remove lead compounds from paints and petrol in most high-income countries, it remains a persistent contaminant of the plastic polyvinyl chloride, brass tap fittings, children's toys and even food. A 1983 report by the UK Royal Commission on Environmental Pollution found that lead was so widely dispersed in the environment, owing to its extensive use during the twentieth century, that "it is doubtful whether any part of the earth's surface or any form of life remains uncontaminated by anthropogenic lead".

Faced with the impossibility of fully cleansing the environment of lead, regulatory bodies instead try to minimize people's exposure to it by setting legally acceptable levels. But often, such levels are not based on scientific evidence, and what is deemed allowable can vary considerably from place to place. For example, the Australian standard for brass pipe fittings permits a lead content of $4.5 \%$, whereas the equivalent US limit is $0.25 \%$. "The problem with lead lies in the regulatory systems that insist on allowing theoretical, but not empirically supported, safe levels," says Mark Taylor, who studies environmental contamination at Macquarie University in Sydney, Australia.

Therefore, despite decades of research into its effects and attempts at regulation, lead continues to permeate the environment and to cause serious health problems - even in the most advanced countries in the world. A 2016 study found tap water contaminated with lead in more than half of 212 homes tested in the state of New South Wales, Australia. And in 2014, a crisis was seeded in Flint, Michigan, when the city's water supply was switched to the Flint River. The local authority failed to treat water from this new source with an anti-corrosion agent, which resulted in lead leaching from water pipes. The result was broad public exposure to unsafe levels of lead - almost 900 times the legal limit, in some cases - with devastating consequences for many unborn children. The Flint crisis prompted a number of investigations into water quality and lead poisoning in other parts of the United States. "The results indicated that childhood lead exposure in Flint is more the norm than the exception," says Bellinger. 


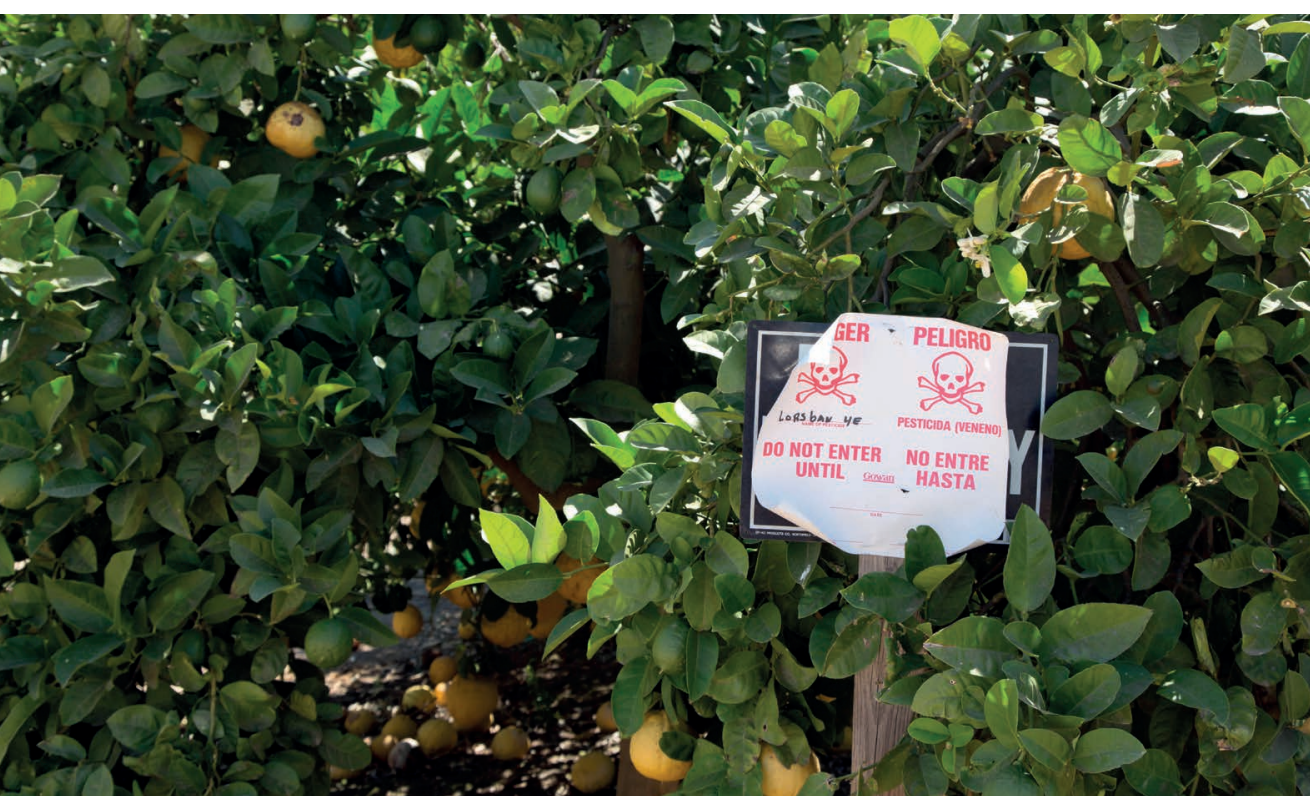

A sign warns that the pesticide chlorpyrifos has been applied to an orange orchard in California.

Indeed, he adds, many areas of the United States have an even greater prevalence of children with high levels of lead in their blood.

\section{CHEMICAL WHACK-A-MOLE}

In some cases, strong action founded in evidence can be taken against a chemical pollutant and still not yield the health improvements that were intended. Bisphenol A (BPA) is a substance found commonly in the liners of food tins, plastic water bottles and even the thermal paper on which shop receipts are printed. BPA's structure enables it to mimic or block the action of hormones. This allows the molecule to interfere with the function of the body's endocrine system - the complex network of glands, hormones and receptors that link the brain to reproduction and metabolism.

The detrimental impact of BPA is well established; evidence of its hormone-disrupting capabilities began to emerge in the mid-1930s. Numerous studies of its toxicity in people and animals eventually led several manufacturers to remove the chemical from their products. Unfortunately, the compounds that manufacturers now use instead of BPA are not much safer. "Replacement chemicals

"When
science and
court action
builds enough
pressure,
it occludes
industry
voices."
may be as bad, or even worse, than BPA," says Andrea Gore, a toxicologist at the University of Texas at Austin. "The chemical industry has switched to other members of the bisphenol family, but recent studies testing these bisphenols show that they are also endocrine disruptors," she says.

"Some have made the analogy to chemical 'whack-a-mole', whereby we try to increase human safety by regulating one chemical, only to see several similar chemicals pop up to replace it," says Martin. Comparable issues have been reported for other toxic chemicals, including phthalates, per- and polyfluoroalkyl substances and flame retardants.

In each case, the initial response of manufacturers was to replace a regulated chemical with something similar. And because the properties of a material are linked directly to its chemical structure, such replacements often had similar effects on health. "It's easier and faster for the manufacturer to replace the restricted chemical with other existing chemicals having similar shapes, sizes and properties," says Martin. "This is not necessarily nefarious but it is dumb, and the best chemical regulatory systems in the world allow it to happen again and again."

\section{POLICY SHIFT}

To minimize the adverse effects of pollution on health, many researchers recommend that people take matters into their own hands by limiting personal exposure to toxic chemicals. Exposure to BPA and its replacements can, for instance, be reduced considerably by avoiding tinned foods. And the consumption of pesticides can be reduced through careful preparation of fruit and vegetables, or by choosing organic produce grown largely without the use of synthetic substances.

But lifestyle changes have only a limited reach. "While behavioural modifications can reduce exposure, modifications in industrial practices are also likely to produce substantial reductions," says Leonardo Trasande, a paediatrician at New York University Langone Medical Center.

Some researchers are calling for the toxicity of a chemical to be established in advance of its introduction to the environment. "The idea that a chemical should be thoroughly tested for toxicity before it goes on the market seems like a no-brainer, but that simply isn't how we regulate chemicals in the United States," says Gore. "The burden of proof should be on those who are profiting from the chemicals," she adds. Assessing the safety of a chemical takes a long time, however - an observation that led Philippe Grandjean, an environmentalhealth researcher at the University of Southern Denmark in Odense, to suggest lowering the bar researchers must clear to prove a chemical is unsafe. "We have to decide whether we need to wait many years or decades for solid proof, or if less documentation would be required in the interest of preserving the next generation's brain functions," he says.

To achieve considerable change in the way that pollutants are regulated worldwide, Gore thinks that pressure from the public will be crucial. "The way to change things is for people to vote for politicians who take strong proenvironmental stands," she says. Many of the positive steps already taken to protect people from harmful pollutants are rooted in heightened public awareness and the pressure that it exerts. BPA, for example, was banned from use in baby bottles by the US Food and Drug Administration (FDA) in 2012 after the American Chemistry Council requested the move to allay concern from the public. Between 2006 and 2015, per- and polyfluoroalkyl substances were phased out by chemical manufacturers and the EPA, against a backdrop of mounting public pressure that included a lawsuit against one manufacturer. And in Beijing, pressure exerted through Chinese social media - including the sharing of air-quality data collected by the US embassy - has been instrumental in prompting the authorities to begin to address the problem of air pollution.

"When science and court action builds enough pressure, it occludes industry voices," says Taylor. Dogged determination is required to ensure that promises are fulfilled, he adds, but the combination of incontrovertible evidence and public engagement offer the best hope of eliminating toxic pollutants and protecting health. "Humans are both the problem and the solution. The challenge facing scientists and policymakers is how to get the wider public to see and engage actively," he says.

In January, as a petition with more than 30,000 signatures circulated and demands from concerned customers mounted, a large chain of hardware stores in Australia and the United Kingdom revealed its intention to phase out the sale of a neonicotinoid insecticide that is linked to declining bee populations. "Now people are pressuring companies to ditch plastic, or taking legal action against governments to take new measures against long-overdue air-pollution problems," says Taylor. "Everybody can play a role in reducing pollution," he adds. "It is the cumulative impact of all our efforts that is important."

Karl Gruber is a freelance science writer in Perth, Australia. 